\title{
Design of Book Management Information System
}

\author{
Lei Xiong ${ }^{1}$, Qiangjun Kuang ${ }^{2}$ \\ ${ }^{1}$ College of Information Engineering, Jiangxi University of Technology, Jiangxi Nanchang \\ ${ }^{2}$ Jiangxi technology bussiness polytechnic
}

Keywords: Book management; Management information system; Information technology; library

\begin{abstract}
In order to improve the efficiency of the library book management, promote the standardization, systematization and routinization of book management and lending work, avoid arbitrariness of book management, improve the speed and accuracy of information processing, inquire and modify book information timely, accurately and effectively, the paper first analyzed the feasibility of solution to the problems from the technical, economic, practical and legal aspects, made the general design, designed the function module in detail, and finally made the software testing. The system designed in the paper includes information query module, book management module, initialization module, and information release and management module, which can not only improve the efficiency of book management, but also greatly improve the security of book management.
\end{abstract}

\section{Overview}

As the collecting and distributing center of information resource, library has lots of books and lending materials for users, which involve the management of various information data. Nowadays, many libraries have been put into use for not a long time, and computers are not even applied in the information management of the library. According to the survey, the previous information management is mainly through the manual processing based on paper medium such as text, tables, etc; the statistics and verification of book lending situation such as the number of lending days and the number of overdue days of limiting borrow time, are usually completed by human inspection on library card; the reading privilege and lending days are confirmed by human calculation and hand writing. It is error-prone because of the large data information process workload; it is easy to lose and difficult to inquire due to various data. Although some libraries have computers, the computers are used for information management; the effectiveness of computers is not well played, and the problem of idle resources is prominent; the achievement of modern science and technology is not fully utilized.

The ultimate goal of book management information system is to achieve the standardization, systematization and routinization of book management and lending work, a void arbitrariness of book management, improve the speed and accuracy of information processing, inquire and modify book information timely, accurately and effectively. The use of library public access management information system can not only improve the work efficiency, but also greatly improve its security. 


\section{Feasibility study}

Feasibility study is to analyze the possible solution to the problems from the technical, economic, practical and legal aspects. The purpose of the feasibility study is to determine the feasibility of system target and scale described in the definition stage with minimum cost and within shortest time, whether it can be solved or deserves to be solved.

Feasibility study essentially is the process of system analysis and design which have been greatly compressed and simplified, namely the process of system analysis and design by more abstract way at a higher level.

Investigation on current system. The target of current system

Books management information system is one kind of information system designed for urban library to handle lots of readers' information, book information, the information of borrowing from the interaction between readers and book, and information of returning books. The manual operation of data processing has the defects of large workload, high error rate and difficult modification after making mistakes. Library adopts manual ways to manage the book borrowing; due to lots of information, the management of book borrowing information is disordered and complicated; the borrowing information is generally recorded in the library card, and the number and title of books are recorded in the file; the staffs and administrators of libraries are temporarily clear about the information, and they need to search and inquire in numerous data over time, which wastes time and energy. It will be much more difficult to modify the information of books that is lent long time ago.

Based on the problem, the author believes that it is necessary to establish a book management system in order to achieve the standardization, syste matization and routinization of book management, avoid arbitrariness of book management, improve the speed and accuracy of information processing, inquire and modify book information timely, accurately and effectively. The system will manage the information resources such as books retrieval, new book notification, information release, messages and announcements, as well as the reader resources, book resources, information of borrowing and returning books; it can timely acquire the information modification in each link, and be in favor of improving management efficiency.

\section{Organization}

The organization of library includes the office of chief librarian, acquisition and circulation department, periodical reading department; acquisition and circulation department includes acquisition department, library circulation desk, sample warehouse, etc.; periodical reading department includes current periodical reading room, outdated periodical reading room, etc.

The acquisition and circulation department of library is mainly responsible for the operation service such as book acquisition, book sorting and cataloguing, book reservation, and form of catalogue, and lending work of books and documents; the book ading department is mainly responsible for the management of books and book reading work.

The organization chart of library is shown in chart $2-1$ : 


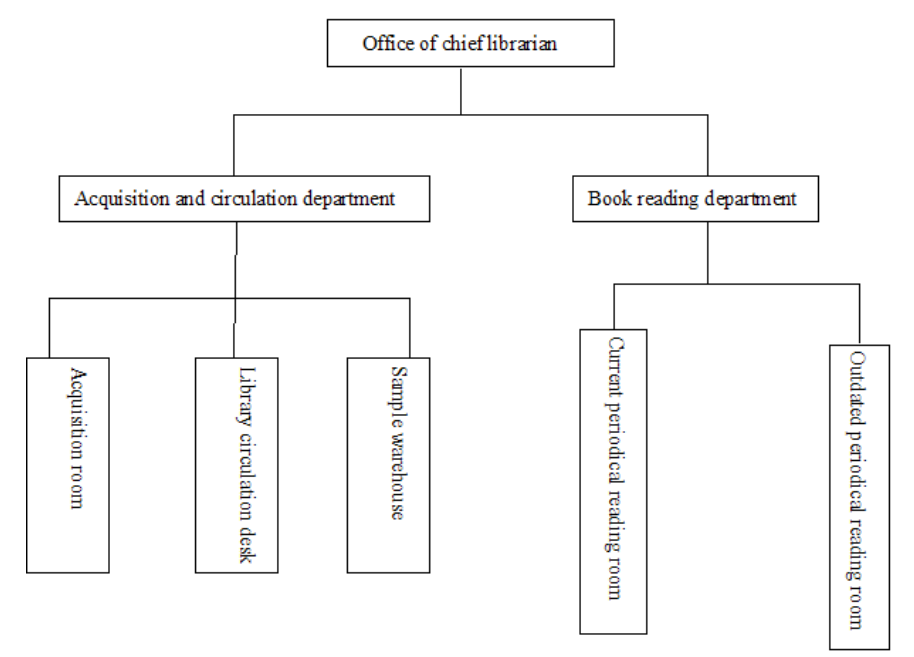

Fig. 2-1 the library organization chart

The business process chart of system

In order to clearly describe the business process of system, the business process chart is adopted and shown in chart 2-2:

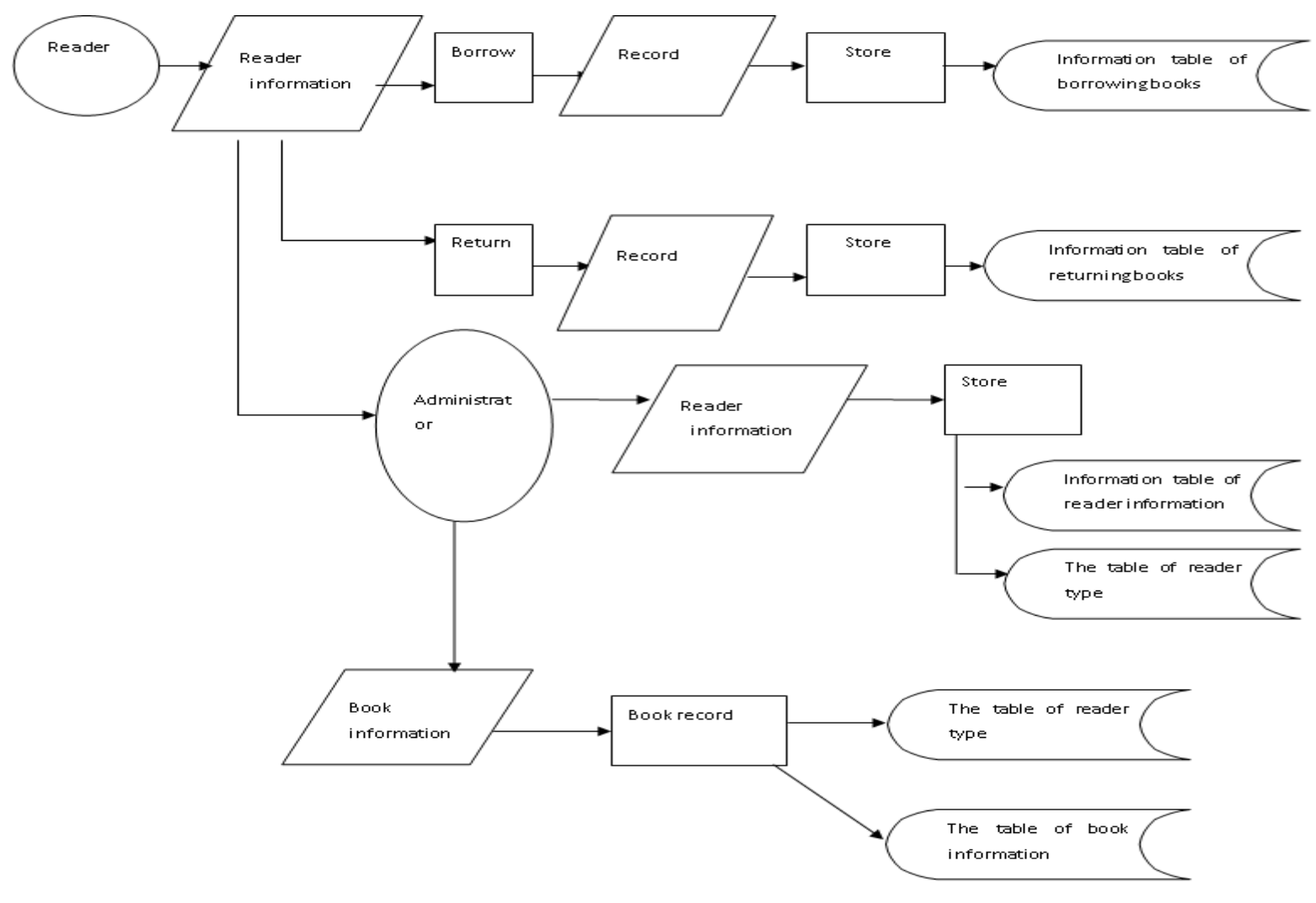

Fig. 2-2 business process chart of management information system

Feasibility analysis. The purpose of feasibility analysis

Feasibility study is to analyze the possible solution to the problems from the technical, economic, practical and legal aspects. The purpose of the feasibility study is to determine the feasibility of system target and scale described in the definition stage with minimum cost and within shortest time, whether it can be solved or deserves to be solved.

Feasibility study essentially is the process of system analysis and design which have been 
greatly compressed and simplified, namely the process of system analysis and design by more abstract way at a higher level.

Feasibility of operation

The use of this software requires certain basic knowledge of computer, and the system administrator is required to have professional knowledge on computer; the manager will receive general training; staffs can use the software skillfully; the system administrator will receive professional training, and he or she can be proficient in system management after training.

Legal feasibility

The software development process is completed by original design philosophy of designers, and there is no plagiarism in the process. All technical data are kept properly by the developers in order to prevent theft and reproduction and protect the developer's intellectual property rights.

To sum up, the system is legally feasibly from all aspects. Because the investment-benefit ratio is more than $100 \%$, the system can be developed.

\section{Demand analysis}

Function description of book management information system. Books management information system is mainly to complete the retrieval of book information, reservation, new book notification check, and information feedback from readers and the management of reader information, book information and lending information and maintenance from librarian. The librarian deals with large amount of information, and the data requires highest security and confidentiality. This function achieves management and maintenance of book information, reader information and lending information. Library administrators can inquire, add, delete, modify the basic information of the book and readers, inquire the lending information, issue the new book notification, check and manager the readers' message, etc. In combination with the requirements of the library, the author conducted in-depth study and application on the MS SQL Server2000 database management system, SQL language principle, Power Buider 9.0 application program design, Power Buider 9.0 database technology, mainly completed the demand analysis on book management system, functional module division, and database module analysis, and designed the database structure and application program. In this paper, the design of library management information system can help the librarian to realize the management such as readers, books, lending information and maintenance, achieve the standardization, systematization and routinization of book management work, avoid arbitrariness of book management, improve the speed and accuracy of information processing, inquire and modify book information timely, accurately and effectively.

Performance description of book management information system. The book management system software completed by this design has relatively perfect function, and the advantages are convenient and high-efficiency data manipulation and high integration such as document integration, data integration, modular structure, as well as convenient system maintenance. This software is developed with powerful database software development tools, has good and wide practicability, and is easy to transplant. Based on the platform of c/s mode system operated in Windows environment, the interface is friendly and easy to operate. 
Logic model of book management information system. Data flow diagram of book management information system is also called DFD, and it describes the logical structure of target system, which is consisted of the entity, processing, data storage and data flow. In order to make the logic structure described in data flow diagram more clear and easy to read, the symbol description of data flow diagram is shown in Fig. 3-1:

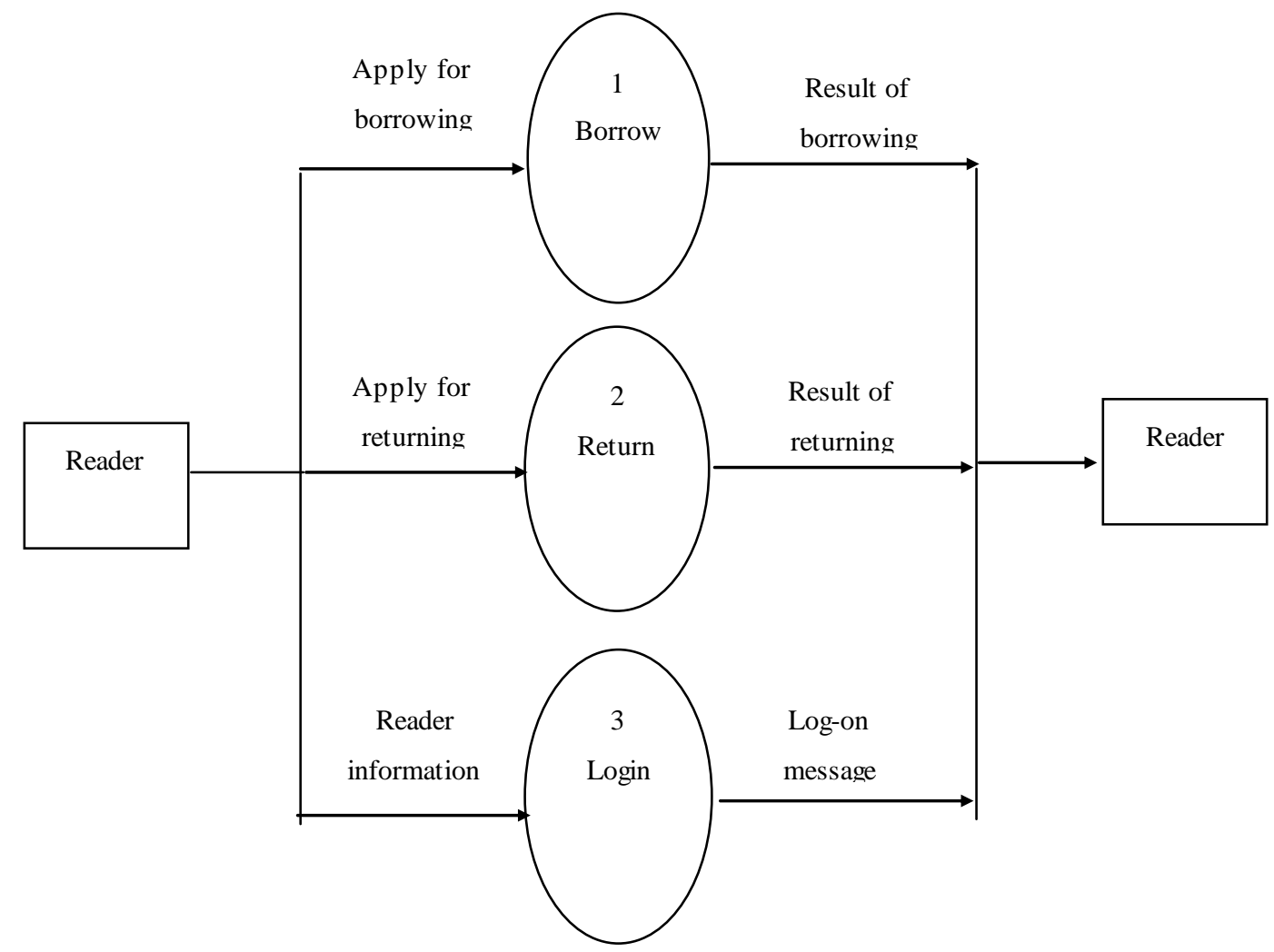

(a) First layer of data flow chart 


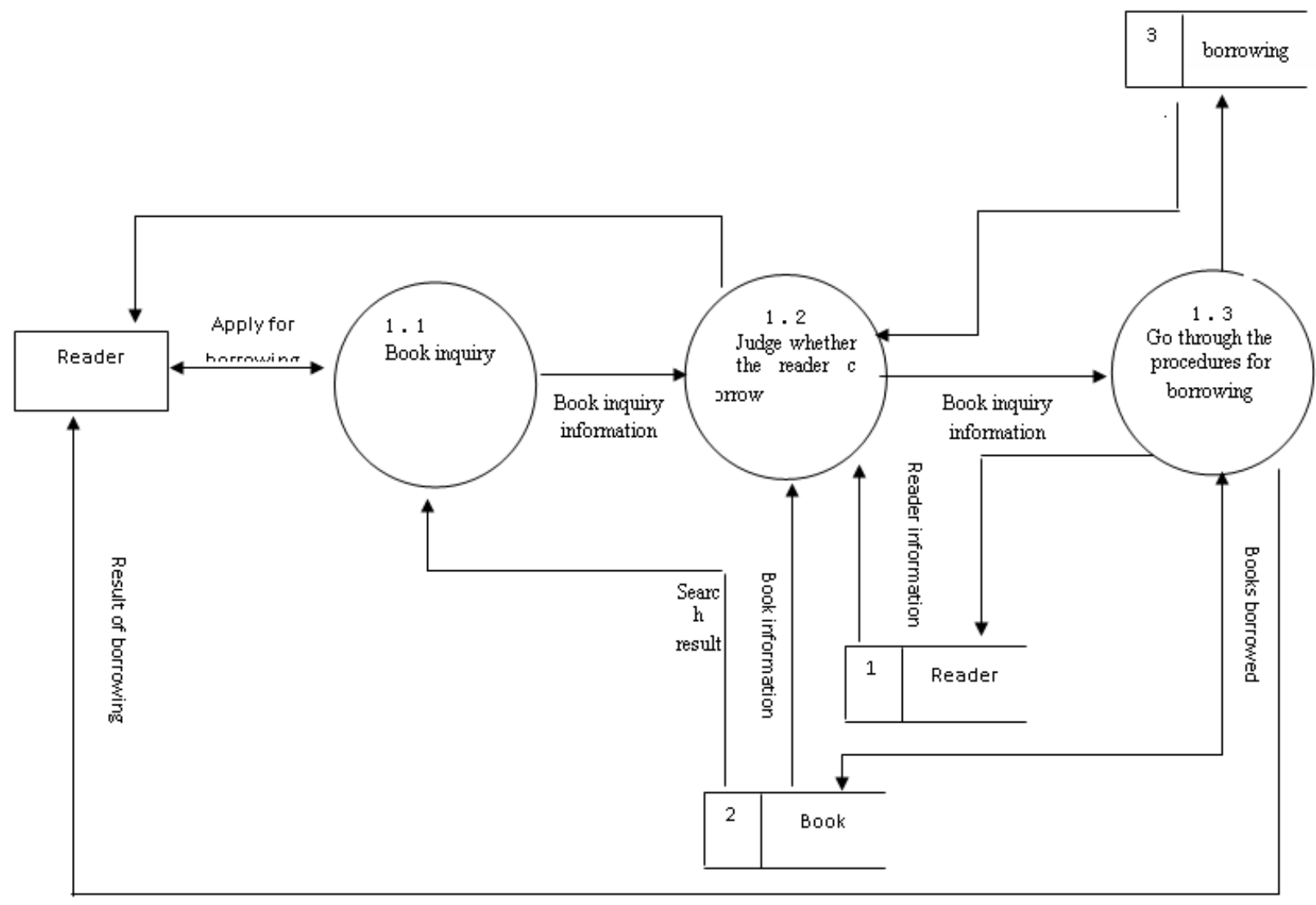

(b) Borrow book (c) Return book

Fig. 3-1 data flow chart of book circulation

\section{Overall design}

Design philosophy. In the overall design process, find out the various solutions to the target system, and make requirements analysis on the acquired data flow chart of each phase, which is the basis of every possible solution. Disassemble the overall requirement goal according to the function, and the requirement goal includes information inquiry, book management, system initialization, and information release. Therefore, this system is composed of four modules; each module has their own function, and the four modules all have the inquiry and adding function. The data of each module are all stored in database; the call and connection of data are all completed by program.

Usually, a module in the program will complete an appropriate sub-function. The module should be organized into a good hierarchy system; top-level module calls its lower-level module so as to realize the complete function of the program; each lower-level module will call further lower-level module to complete the sub-function of program, and the lowest-level module completes the most specific functions. The software structure, namely the hierarchy system organized by module, can be described by hierarchical graph or structure chart, and the HIPO diagram of this system is shown below.

HIPO describes the hierarchy system of module organization; HIPO chart can easily describe the input data, process data and the relationship with output data. HIPO chart uses few and simple basic symbols, and it contains some additional information. The HIPO chart of this system is shown in Fig. 4-1. 
Software structure chart of book management information system. After administrator logs in, HIPO chart is shown as follows:

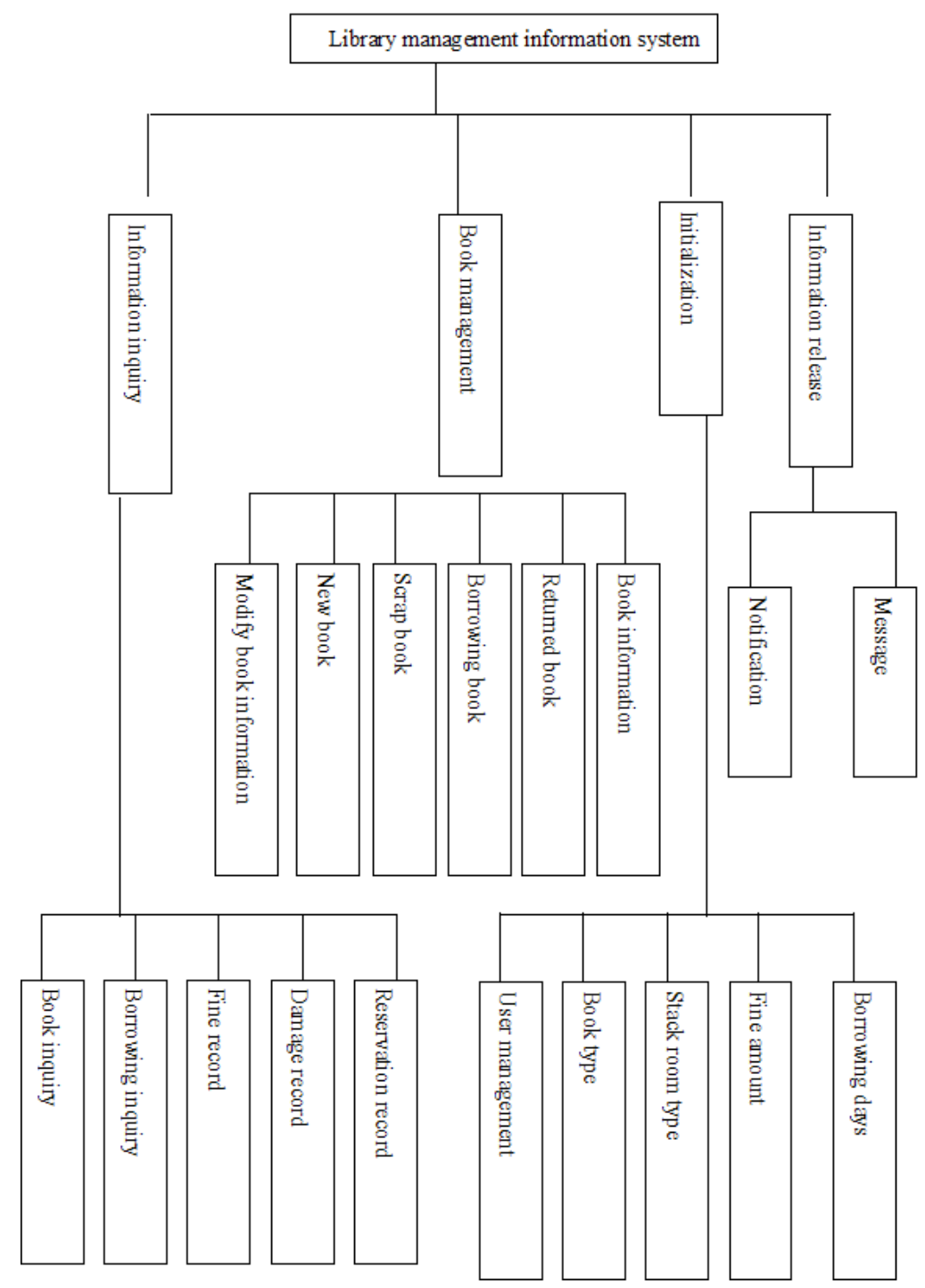

Fig. 4-1 software structure chart of book management information system after the login of administrator

After the log in of readers, the HIPO chart is shown in 4-2 as follows:

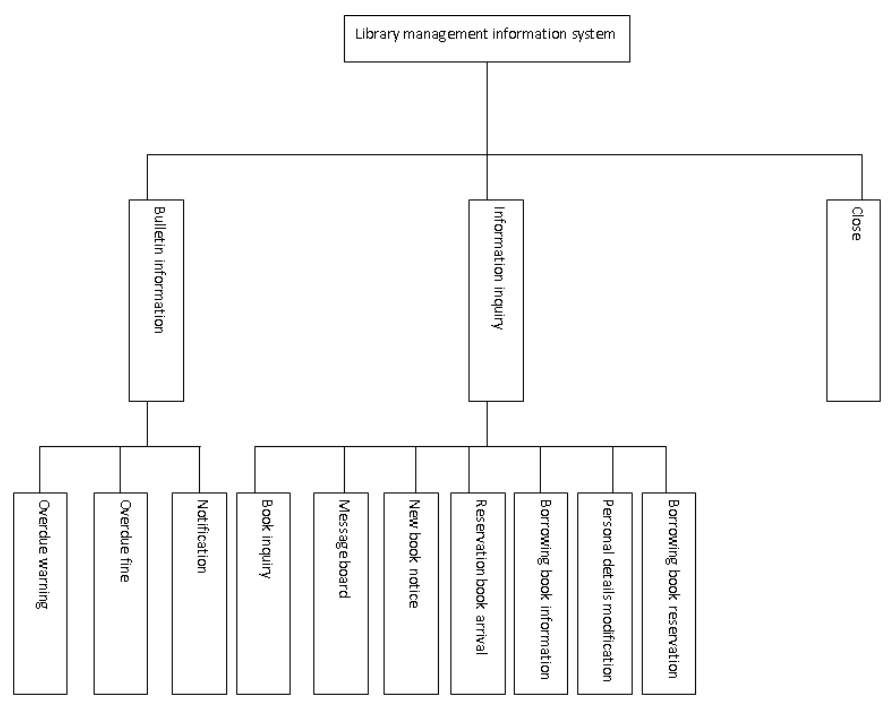

Fig. 4-2 HIPO chart of book management information system after the login of reader 
Module description of book management information system. This system is divided into four modules, and they are information inquiry module, book management module, initialization module, and information release management module.

Description of information inquiry module

Function: book inquiry, borrowing book inquiry, fine record inquiry, damage record inquiry, and reservation record inquiry.

After the login of information inquiry management module, according to the need, administrator selects query item, enters query conditions, and completes relevant inquiries. For example, the book inquiry can be done by entering the information such as serial number of books, title and press, which can be accurate or fuzzy; borrowing inquiry can be done by borrower number or the time range of borrowing; fine record inquiry, the damage record inquiry, and reservation record inquiry can be done by serial number of books or time range.

Description of book management module

Function: add book information, modify book information, delete book information, process borrowing book, process returned books, description of book information.

Adding books means to complete the input of new book information; modifying books means to modify the book record in storage; deleting book information is about the scrap books; processing borrowing book is to enter the serial number of reader and book when the reader borrows books; returning book is to complete the operation of reader returning book; book description is the detailed instructions of books.

Description of initialization module

Function: reader management, user management, book type, category design, the setting of fine amount and borrowing days.

"Reader management" is about newly building or deleting reader information; "book type" is about newly building or deleting book type; "stack room type" is about inserting or deleting stack room type; "fine amount" finishes the operation of readers with overdue books still in use and damaged books; "borrowing days" finishes the setting of default borrowing days.

Description of information release management module

Function: manage the information of library notice and user message.

Notice is relevant information issued to all the readers, such as close for a period of time due to some reason, the opening time, and so on. The management of user message is to inquire the message, and delete outdated or meaningless messages.

\section{Test design}

Basic principle of system test. The development system adopts module design scheme for top-down testing:

(1) In the main control module testing, stub program replaces all the modules that directly belong to main control module;

(2) According to the combination strategies of options, depth-first or breadth-first, one practical module replaces one stub program each time;

(3) Do the testing while entering one module together;

(4) In order to guarantee no new errors when joining module, probably the regression test is needed (repeat in whole or in part previous test). 
Starting from the second step, repeat the above process until the whole software structure is completed.

Unit testing of book management information system. Firstly, test each module in the system; if the in-out of data is not right, all the other testing is impractical. In the module test, the main testing aspects are the number of parameters, sequence, attributes, or whether the unit system is consistent with variable, whether the variable only for input is modified, whether the definition and usage of the global variable is consistent with each module.

Secondly, local data structure is a common source of error for module. Test scheme should be carefully designed so as to find the errors of local data such as description, initialization, and default value.

Thirdly, due to the general impossible exhaustive testing, during unit testing, choose the execution path that is most representative and most likely to find errors.

Finally, do the boundary test

Testing scheme of module input in book management information system

In the book management information system, first choose the common data for testing, and do the next-step testing if possible. Choose the error-prone data for input test; return if there is error and modify the error, and go to the next-step if there is no error. Choose the complex data and input the system, test the system step by step. Adopting the black-box testing introduced in the <Introduction to the software engineering>, in which the program is treated as a black box, and the internal structure and the process of the program is completely ignored. Black-box testing is done in the program interface; it only tests whether the program function can be normally used in accordance with the specification, whether the program can output correct information by receiving input data appropriately, and guarantee the integrity of the external information such as database and file.

Reader module output result prediction in book management information system Choose general data to input the system, and detect whether the output result is consistent with the expected results; if not consistent, detect system and find the problem; if consistent, choose error-prone data and deliberately complex data to input system; test the output results, and detect the system again until find faults if not consistent.

3. Module test result prediction in book management information system

(1) Test records

Passed the validation of administrator privileges successfully, successful made use of all the functions of users and administrators, and successfully modified the background database and get correct results.

(2) Results analysis

Passed the test successfully, operated normally, with use value, it can be put into use and play a role in the management system of scientific research project.

System maintenance suggestion. First, operator must be proficient in computer operation.

In the operation of the system, keep voltage stable so as to prevent the failure of information preservation due to instable voltage. Check whether information is saved after operation. Maintain the database management timely and prevent data loss. 


\section{Conclusions}

Book management information system can make the administrator easily, accurately and quickly record the condition of reader type, reader information, book type, basic book information, borrowing book information, and returned book information. Readers can log in the system as user and inquire information; administrator can modify and delete the previous recorded information. This book management system software is a kind of data management software that has relatively perfect functions, is convenient and high efficient in data operation. This software is developed by database software development tools with powerful functions, has good portability, and can be applied in the Windows operating system that has a wide range of application.

\section{Acknowledgements}

This work was financially supported by project of Technology Department of Jiangxi Province [No 20143BBM26048]and project of Jiangxi University of Technology [No. xtcx201312].

\section{References}

[1] Hu Chunan, Hu Zhongdong, Xia Dongmei. Design of book management system software. Information technology, 2005.40 (1) 98 102

[2]Comrade studio. Examples of Power Builder 9.0 database development (Second edition). Beijing: Posts and Telecom Press, 2001.11 12

[3] Ye Qiang. Brief analysis on the existing problems and countermeasure to library management information system. Journal of Library and Information Sciences in Agriculture, 2005.42(2): 126 129

[4] Huang Shiyang. Introduction and example of Power Builder 9.0(First edition). Dalian: Dalian University of Technology Press, 2003.6 7

[5] Yue Guoying. Practical guide to SQL Server 2000 database technology (First edition). Beijing: China Electric Power Press, 2005.19 21

[6] Sa Shixuan. Design of introduction to database system (Third edition). Beijing: Higher Education Press, 2000.11 17

[7] Zhang Haifan. Introduction to software engineering (Fourth edition). Beijing: Tsinghua University Press, 2003.12 14

[8] Zhang Fengqin. Database principle and application (First edition). Beijing: Tsinghua University Press, 2005.2

[9] Wiederhold G. Database Design (second Edition).McGraw-Hill, 1983.3

[10] Camil Demetrescu,Ginseppef. The information technique to the system sciences work influence.Italiano.Journal of computer and system sciences,2006. Feb (7) : 25 26 